\title{
DISABILITY MEASURES AS AN INDICATOR OF POVERTY: A CASE STUDY FROM VIET NAM
}

\author{
MICHAEL G. PALMER ${ }^{1 *}$, NGUYEN THI MINH THUY ${ }^{2}$, QUACH THI NGOC QUYEN ${ }^{3}$, \\ DANG SY DUY ${ }^{4}$, HOANG VAN HUYNH ${ }^{5}$ and HELEN L. BERRY ${ }^{1}$ \\ ${ }^{1}$ National Centre for Epidemiology \& Population Health, Australian National University, \\ Canberra, Australia \\ ${ }^{2}$ Department of Community-Based Rehabilitation, Hanoi School of Public Health, Hanoi, Viet Nam \\ ${ }^{3}$ Catholic Relief Services, Hanoi Office, Hanoi, Viet Nam \\ ${ }^{4}$ Long Bien District Health Centre, Hanoi, Viet Nam \\ ${ }^{5}$ Hai Duong Provincial Health Department, Hai Duong, Viet Nam
}

\begin{abstract}
This paper examines the relationship between disability and poverty at a healthdemographic surveillance site in Viet Nam using alternative measures of disability severity. Analysis of the site population $(n=65400)$ is combined with interviews of 27 households containing members with disabilities. Results show that disability severity is positively associated with poverty. Results support recent efforts of the Vietnamese government to extend programmes of social protection for households containing members with severe disabilities. However, a higher level of disability targeting is required, both in terms of eligibility and of benefit levels. Copyright (C) 2010 John Wiley \& Sons, Ltd.
\end{abstract}

Keywords: people with disabilities; poverty; social protection; Viet Nam

\section{INTRODUCTION}

People with disabilities (PWDs) are thought to represent a disproportionately high proportion of the world's poor population (United Nations, 2006). Disability has thus been flagged as a key development issue in meeting the United Nations Millennium Development Goals and eradicating world poverty (Kett et al., 2009). Despite the acknowledged links between disability and poverty, few empirical studies have systematically examined the economic costs of disability and their implication for household welfare (Elwan, 1999; Haveman and Wolfe, 2000; Braithwaite and Mont, 2008). This is particularly the case in low- and middle-income countries where the majority

*Correspondence to: Michael G. Palmer, PhD Candidate, NCEPH, Building 62, ANU, Canberra ACT 0200, Australia. E-mail: michael.palmer@anu.edu.au 
of PWDs live, representing a considerable information gap to formulate programmes of social protection.

A less recognised problem is that PWDs are typically treated as a homogenous group despite evidence that disability severity is a significant correlate with poverty (Braithwaite and Mont, 2008). Furthermore, severe disability is a common eligibility requirement of social protection programmes. As Gooding and Marriot (2009) noted in a special issue of this journal, statistics on disability are generally collected using criteria different to those used for eligibility for social protection programmes. The efficacy of disability targeting in programmes has thus been limited (Mitra, 2005; Gooding and Marriot, 2009). In highincome countries discrete disability programmes are common. However, in settings where resources and administrative capacity is limited disability targeting is typically incorporated into mainstream social protection programmes (Mitra, 2005).

Using data from a health-demographic surveillance site in northern Viet Nam, known as the CHILILAB, this paper examines the relationship between disability and poverty using alternative measures of disability severity. The effectiveness of current mainstream social protection programmes for PWDs is subsequently assessed. The study combines descriptive analysis of the disabled versus non-disabled site population with semistructured interviews of 27 households with disabled members. Two measures of disability are applied including a broad measure of functioning, based upon contemporary international classification, and a higher order functioning measure of the ability to perform a selection of daily activities.

\section{OVERVIEW OF DISABILITY, POVERTY AND SOCIAL PROTECTION IN VIET NAM}

Viet Nam has a large disabled population. The government estimates at least 5.3 million Vietnamese people (6.6 per cent of the population) are living with a disability (MOLISA, 2006). An alternative estimate, using an international general measure of disability contained in the Viet Nam Household Living Standards Survey 2006, puts this number at 12.9 million people (15.3 per cent of the population) (GSO, 2008). Viet Nam is susceptible to disabling conditions due to disease, accident, deprivation and low use of formal healthcare. Lack of rehabilitation services also contribute substantially to disability (MOLISA, 2006). Injuries acquired as a result of war are estimated to account for approximately one-quarter of the disabled population (estimate includes post-war victims of Agent Orange, landmines and unexploded ordinance) (MOLISA, 2006).

Although a number of studies have examined poverty among the general population and subpopulations including ethnic minority people and the elderly in Viet Nam (van-deWalle, 2001; Joint Donor Group, 2003; Glewwe et al., 2004; Giang and Pfau, 2009), detailed poverty analysis is yet to be performed for PWDs. According to a government report, 32.5 per cent of households with PWDs are living below the poverty line (MOLISA, 2006). Poverty estimates are derived from household income equivalised per capita. They do not delineate the loss of household income attributable to incapacity and care-giving nor account for additional costs associated with disability, such as healthcare, which can greatly accentuate poverty status. Furthermore, there is no breakdown by disability severity or other poverty correlates.

In Viet Nam, the legal responsibility to protect and assist PWDs is shared between the family, state and community (Ordinance on Disabled Persons, 1998). During the last 
decade, the government has implemented social protection measures designed to improve access to healthcare and protect the livelihoods of certain target groups (Le et al., 2005). PWDs are among a list of policy beneficiaries including meritorious persons, orphans, the elderly (85 years above) and persons living with HIV/AIDS, etc. (Regulation 67, 2007). Like other policy beneficiaries, people with severe disabilities that live in poor families are entitled to some free healthcare and monthly income support (Ordinance on Disabled Persons, 1998). The coverage and effectiveness of these programmes for PWDs is not clearly documented.

\section{METHODS}

\subsection{Study Site}

Established in July 2004, the CHILILAB is 1 of 37 health-demographic surveillance sites in 18 developing countries in Africa, Asia and Oceania under the INDEPTH Network whose mission is to 'provide a better, empirical understanding of health and social issues, and to apply this understanding to alleviate the most severe health and social challenges'. ${ }^{1}$ The CHILILAB is located in the district of Chi Linh, Hai Duong province, a mountainous region approximately $60 \mathrm{~km}$ northeast of Viet Nam's capital, Hanoi (HSPH, 2008). The site consists of seven communes (three urban, four rural) with a population of approximately 65400 and 17900 households. Baseline demographic and socio-economic data on the site population is collected every 2 years with quarterly updates of immigration, reproduction, marital status, morbidity, mortality and injury. Research findings, including risk factors for non-communicable diseases, prenatal healthcare service utilisation, burden of disease and others, have been published by the Hanoi School of Public Health (HSPH, 2008).

Characteristics of the site are typical of many regions in Viet Nam (HSPH, 2008). Urban areas are densely populated with arterial bitumen roads and small-scale trading as the primary economic activity amid local industries of thermal power, glass manufacture, clay mining and shoe leather processing. Rural areas are more sparsely populated with limited infrastructure and mostly gravel roads. Agriculture is the main source of income in rural areas with irrigation provided by the Kinh Thay River. The main food crop is rice with subsidiary dry-food crops of maize and groundnuts. Over the last 10 years the growing of commercial fruit trees such as lychee, longan and custard apple has expanded. All households at the site have access to electricity and the overwhelming majority (99.6 per cent) of people are Kinh (the main ethnic group of Viet Nam). Health facilities consist of commune health stations and a district public hospital, as well as numerous private clinics and pharmacies (Figure 1).

\subsection{Data}

Data derived from a disability survey of the site population conducted in 2007 for a project supported by the China Medical Board of New York into the social and health needs of PWDs. The survey collected extensive information on healthcare usage (including

\footnotetext{
${ }^{1}$ For further information on the CHILILAB and INDEPTH Network refer http://chililab.org and http://www. indepth-network.org/index.php?option=com_content\&task=view\&id=13\&Itemid=28.
} 

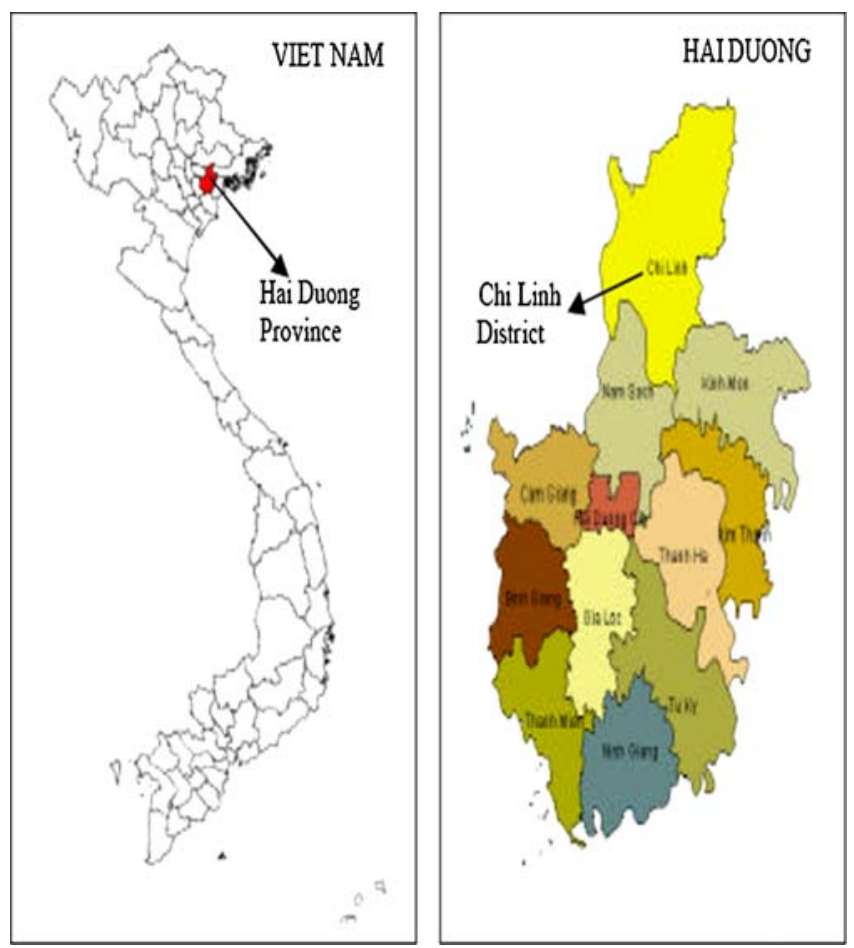

Figure 1. Chi Linh district, Hai Duong province This figure is available in colour online at www.interscience.wiley.com/journal/jid

rehabilitation and assist devices), daily caring requirements, informal and formal supports received, and level of participation in production-related activities. Baseline site socioeconomic data, including age, sex, education level, occupation, household assets and poverty, was merged with disability data. In addition, 27 households with PWDs of working age (18-50 years) in two communes (one urban and one rural) participated in semi-structured interview to detail the processes linking disability and poverty. The majority (22) of PWDs were severe in degree with five persons with non-severe disabilities included as a control. ${ }^{2}$ Interviews were structured around four inter-connecting themes: (i) economic costs of disability, (ii) household coping mechanisms, (iii) informal and formal supports and (iv) household health and welfare. Consistent with Glendinning and Baldwin (1988) three main economic costs of disability were examined including foregone income from disabled member/s, foregone income from primary carers and additional costs attributable to disability which we limit to healthcare utilisation as a significant cost commonly associated with disability (Haveman and Wolfe, 2000). An important factor affecting household poverty and welfare relates to the coping mechanisms employed to manage the economic costs of disability including the uptake of informal and formal protections.

\footnotetext{
${ }^{2}$ Other selection criteria included impairment type, sex and rural/urban location as reported determinants of poverty (Elwan, 1999). Consistent with national distribution, impairment types were mostly mobility (11) and mental (13) with the remainder hearing and speaking (2) and epilepsy (1) (MOLISA, 2006). Approximately half of PWDs were female and half were from urban areas. Most (all but two) households participating in this study contained only one PWD in line with the national and site average.
} 


\subsection{Methodology}

\subsubsection{Methods}

Since many of the basic facts of disability and poverty in developing countries are unknown or have not been systematically addressed, the goal of this paper is descriptive. The analysis is performed in three stages. First, we provide socio-economic profile of the disabled versus non-disabled population using alternative measures of disability severity. Second, descriptive statistics of various need indicators among the disabled population are presented by disability severity. Third, qualitative findings are presented according to the four above-listed themes. The approach is justified to aid understanding of the dynamic relationship between disability and poverty while providing empirical data which are statistically generalisable to the site population. ${ }^{3}$ The life experience and opinions of PWDs and their families are given voice to best ensure that the research reflects their interests (Barnes, 2003).

\subsubsection{Measuring disability}

Two disability measures are applied to reflect different orders of functioning: a general disability measure and a severe disability measure. Influenced by the International Classification of Functioning, Disability and Health (ICF) (WHO, 2001), the general disability measure included a range of questions relating to body impairments, functions, activities and participation. PWDs were classified as those who experienced functioning difficulty ('yes' or 'no') in any 1 of 30 questions across 7 domains: mobility, hearing and speaking, vision, learning difficulties, strange behaviour (mental or psychiatric illness), epilepsy and leprosy. This meets a broad policy aim of understanding the extent of disability, but is insufficient to assess the proportion of the population who require rehabilitation and social services. Activities of daily living (ADLs) are a higher order of functioning routinely used as a predictor of a range of health behaviours (including disability) and eligibility for insurance benefits, rehabilitation services and assistedcare living (Weiner et al., 1990; Jette, 1994). Persons experiencing activity limitation were those that required assistance or could not perform with assistance at least 1 of 10 activities. ${ }^{4}$ A human assistance scale was applied as that most suitable to determine service needs: (i) can perform without assistance, (ii) can perform with assistance and (iii) cannot perform (with assistance) (Weiner et al., 1990; Jette, 1994). Note use of aids was not included to measure disability and we excluded people that wear glasses whose only disability was refractive error (long-sighted or short-sighted). The sample included only people aged 6 years and above.

\subsubsection{Measuring poverty}

Two measures of poverty are applied including an asset index and a list of poor households provided by commune officials. An index of asset ownership and housing conditions are at least as reliable as conventional money-metric measures of economic status (Filmer and Pritchett, 2001). The index was based upon ownership of 12 private household assets plus

\footnotetext{
${ }^{3}$ The approach is advocated by Kett et al. (2009, p. 658) who write: 'Something that has become increasingly apparent is the need to understand that the multidimensional aspects of poverty and exclusion for PWDs requires both quantitative and qualitative approaches in order to fully understand the nuances of inclusion and exclusion'. ${ }^{4}$ List of 10 activities include (1) transfer from lying position, (2) transfer from sitting position, (3) walk 10 steps, (4) move about the house, (5) move outside the house, (6) eat and drink, (7) shower, (8) get dressed, (9) go to the toilet and (10) express wants and needs.
} 
those relating to housing conditions. ${ }^{5}$ Assets were weighted using factor analysis and summarised as an index of ascending welfare between -1 and +1 with a mean of zero (refer description Booysen et al., 2008). Households were ranked into asset index quintiles with the lowest 20 th percentile serving as an alternative poverty line to methods applied by local authorities.

\subsubsection{Survey administration and ethical considerations}

The disability survey was administered by 42 local interviewers employed and trained by the CHILILAB. The response rate was 100 per cent for the survey. Two households declined to participate and a further household could not be located for further semistructured interview. Consent to participate was obtained from the household head with information collected from the person with the most knowledge on household matters. Ethical approval for the study was provided by the Vietnamese Ministry of Health and Hanoi School of Public Health (Protocol no.: 62/2007/YTCC-DH3) and the Australian National University (Protocol no.: 2006/0318).

\section{RESULTS}

\subsection{Summary Statistics}

Approximately 18.5 per cent of persons over 5 years of age experienced functioning difficulties and 2.1 per cent required assistance in performing activities (hereafter referred as the general total disabled population and people with severe disabilities, respectively, Table 1). By both poverty measures, PWDs experienced higher rates of poverty than their counterparts without disabilities (55-75 per cent higher depending upon the measure). Absolute rates of poverty across subpopulations were approximately double for the asset index measure compared with the local authority measure. Poverty rates were slightly higher among persons with severe disability.

PWDs also diverged from the site population across a number of poverty correlates (Table 2). PWDs were substantially older (53 years versus 30 years) with 32 per cent over the age of 60 compared with 5 per cent of persons without disabilities. Higher proportion of PWDs were female (59 per cent versus 48 per cent). Illiteracy rates were higher for PWDs ( 7 per cent versus 0 per cent) and they were half as likely to have finished upper secondary

Table 1. Disability prevalence and poverty incidence, CHILILAB, 2007

\begin{tabular}{lccc}
\hline & Non-disabled & \multicolumn{2}{c}{ Disabled } \\
\cline { 3 - 4 } & & Total & Severe \\
\hline Prevalence rate $(\%)$ & 81.5 & 18.5 & 2.1 \\
$(N)$ & $(49523)$ & $(11214)$ & $(1275)$ \\
Poverty measure 1 - local authority register & 8.3 & $14.6^{*}$ & $15.2^{*}$ \\
Poverty measure 2 - lowest 20th asset percentile & 18.0 & $27.9^{*}$ & $30.1^{*}$ \\
\hline
\end{tabular}

${ }^{*} p<0.001$. Estimates apply to persons aged $>5$ years.

\footnotetext{
${ }^{5}$ Private assets (television, refrigerator, radio, video, cupboard, sewing machine, telephone, mobile phone, computer, bicycle, motorbike and car); floor types (tile, cement, earth, other); sanitation types (flush toilet, latrine, other, none) and water sources (piped, well, rain, other). 
Table 2. Poverty correlates among the disabled and non-disabled population, CHILILAB, 2007

\begin{tabular}{|c|c|c|c|}
\hline & \multirow[t]{2}{*}{ Non-disabled } & \multicolumn{2}{|c|}{ Disabled } \\
\hline & & Total & Severe \\
\hline Age (years) & 30.3 & $53.4^{*}$ & $59.4^{*}$ \\
\hline Age groups $(\%)$ & $p<0.001$ & & \\
\hline 1. $6-17$ years & 23.3 & 3.7 & 4.7 \\
\hline 2. $18-60$ years & 72.2 & 64.4 & 44.4 \\
\hline 3. $>60$ years & 4.5 & 31.9 & 50.9 \\
\hline $\operatorname{Sex}(\%)$ & $p<0.001$ & & \\
\hline 1. Female & 48.3 & 59.1 & 59.1 \\
\hline 2. Male & 51.7 & 40.9 & 40.9 \\
\hline Education level completed (\%) & $p<0.001$ & & \\
\hline 1. Illiterate & 0.4 & 7.2 & 17.5 \\
\hline 2. Read and write & 0.8 & 8.0 & 14.1 \\
\hline 3. Primary & 13.2 & 17.3 & 19.2 \\
\hline 4. Lower-secondary & 42.1 & 43.9 & 30.7 \\
\hline 5. Upper-secondary & 22.4 & 11.0 & 7.7 \\
\hline 6. Above secondary & 21.1 & 12.6 & 10.8 \\
\hline Main occupation (\%) & $p<0.001$ & & \\
\hline 1. None & 8.3 & 15.3 & 16.7 \\
\hline 2. Farmer & 30.3 & 49.1 & 41.8 \\
\hline 3. Government official & 11.6 & 5.9 & 6.5 \\
\hline 4. Worker & 14.8 & 5.2 & 5.4 \\
\hline 5. Handicrafts worker & 3.8 & 3.2 & 2.2 \\
\hline 6. Salesperson & 19.8 & 15.6 & 10.8 \\
\hline 7. Other & 11.4 & 5.7 & 16.6 \\
\hline Asset Index ${ }^{a}$ & 0.066 & $-0.247^{*}$ & $-0.274^{*}$ \\
\hline Rural/urban location (\%) & $p<0.001$ & & \\
\hline 1. Urban & 56.3 & 45.6 & 41.6 \\
\hline 2. Rural & 43.7 & 54.4 & 58.4 \\
\hline
\end{tabular}

${ }^{*} p<0.001$. Estimates apply to persons aged $>5$ years.

a Assets include television, refrigerator, radio, video, cupboard, sewing machine, telephone, mobile phone, computer, bicycle, motorbike, car, floor type (tile, cement, earth, other), water source (piped, well, rain, other), toilet type (flush, latrine, other, none). The index was computed using principal-components factor analysis. The percentage of the covariance explained by the first principal-components factor was $19.6 \%$. The first Eigenvalue was 4.71 , the second Eigenvalue was 1.94 .

school or above. PWDs were approximately twice as likely to report no occupation and those that were working were more likely to be farmers (49 per cent versus 30 per cent). PWDs also had fewer household assets and, in contrast to non-disabled residents, the majority lived in rural areas (54 per cent versus 44 per cent).

Whilst little difference in poverty rates was observed by disability degree, persons with severe disabilities differed from the general disabled population across a number of socioeconomic indicators (Table 2). Persons with severe disabilities had higher proportion above 60 years of age (51 per cent versus 32 per cent), illiterate (18 per cent versus 7 per cent), working in 'other' occupations ( 17 per cent versus 6 per cent) and living in rural areas (58 per cent versus 54 per cent) whereas secondary school completion ( 8 per cent versus 11 per cent) and household assets were lower.

Disability severity was positively associated with selected need indicators (Table 3). Two-thirds of persons with severe disabilities had consulted a doctor compared with half of 
Table 3. Need indicators for persons with disabilities by disability measure, CHILILAB, 2007

\begin{tabular}{|c|c|c|c|c|}
\hline & \multicolumn{4}{|c|}{ PWDs } \\
\hline & \multicolumn{2}{|c|}{ Total } & \multicolumn{2}{|c|}{ Severe } \\
\hline & Mean & Std. error & Mean & Std. error \\
\hline Have consulted a doctor (by facility type) & 46.2 & $(0.5)$ & 68.1 & $(1.3)$ \\
\hline 1. Commune health station & 8.9 & $(0.3)$ & 10.6 & $(0.9)$ \\
\hline 2. District hospital & 22.7 & $(0.4)$ & 33.9 & $(1.3)$ \\
\hline 3. Provincial hospital & 12.6 & $(0.3)$ & 19.8 & $(1.1)$ \\
\hline 4. Central hospital & 11.0 & $(0.3)$ & 20.1 & $(1.1)$ \\
\hline 5. Private clinic & 8.3 & $(0.3)$ & 13.5 & $(1.0)$ \\
\hline \multicolumn{5}{|l|}{ Services used by those that sought healthcare } \\
\hline 1. Consultation & 49.1 & $(0.7)$ & 50.8 & $(1.7)$ \\
\hline 2. Rehabilitation & 7.6 & $(0.4)$ & 15.1 & $(1.2)$ \\
\hline 3. Surgery & 12.9 & $(0.5)$ & 13.6 & $(1.2)$ \\
\hline 4. Acupuncture & 34.5 & $(0.6)$ & 31.3 & $(1.6)$ \\
\hline 5. Medication & 52.5 & $(0.7)$ & 60.7 & $(1.7)$ \\
\hline Use an assistive device ${ }^{a}$ & 12.5 & $(0.3)$ & 29.7 & $(1.3)$ \\
\hline 1. Mobility disability & 10.3 & $(0.4)$ & 28.9 & $(1.3)$ \\
\hline a. Crutches & 8.3 & $(0.4)$ & 21.5 & $(1.2)$ \\
\hline b. Wheelchair & 1.0 & $(0.1)$ & 4.5 & $(0.6)$ \\
\hline 2. Visual disability (glasses) ${ }^{\mathrm{b}}$ & 12.6 & $(0.4)$ & 9.7 & (1.4) \\
\hline 3. Hearing and speaking disability (hearing aid) & 2.0 & $(0.3)$ & 1.1 & $(0.6)$ \\
\hline Regularly participate in production-related activities & 71.9 & $(0.5)$ & 49.8 & $(1.2)$ \\
\hline 1. Sometimes & 14.7 & $(0.3)$ & 15.0 & $(1.0)$ \\
\hline 2. Never & 13.4 & $(0.4)$ & 35.2 & $(1.4)$ \\
\hline Require daily care-giving assistance (hours per day) & 5.3 & $(0.2)$ & 25.0 & $(1.2)$ \\
\hline 1. $<1$ & 2.6 & $(0.1)$ & 9.7 & $(0.6)$ \\
\hline 2. $1-3$ & 1.0 & $(0.1)$ & 5.3 & $(0.6)$ \\
\hline 3. $>3$ & 1.7 & $(0.1)$ & 10.0 & $(0.9)$ \\
\hline Receive support from others (by source) & 8.6 & $(0.3)$ & 17.8 & $(1.1)$ \\
\hline 1. Income & 3.8 & $(0.2)$ & 9.1 & $(0.8)$ \\
\hline 2. Healthcare card & 3.7 & $(0.2)$ & 5.8 & $(0.7)$ \\
\hline 3. Assist device & 0.3 & $(0.1)$ & 1.6 & $(0.3)$ \\
\hline 4. Gift & 2.8 & $(0.2)$ & 8.2 & $(0.8)$ \\
\hline 5. Emotional & 2.3 & $(0.1)$ & 6.7 & $(0.7)$ \\
\hline \multicolumn{5}{|l|}{ Income support by source } \\
\hline 1. Government & 2.5 & $(0.1)$ & 4.9 & $(0.6)$ \\
\hline 2. Relatives & 1.2 & $(0.1)$ & 3.5 & $(0.5)$ \\
\hline 3. Neighbours & 0.4 & $(0.1)$ & 2.0 & $(0.4)$ \\
\hline 4. Community organisation & 0.6 & $(0.1)$ & 2.3 & $(0.4)$ \\
\hline
\end{tabular}

${ }^{a}$ Includes people with mobility, visual, and hearing and speaking disabilities only.

' Includes persons with refractive error as the only disability.

Note: Estimates may not sum to total as respondents could enlist more than one category. Estimates apply for persons aged $>5$ years.

all PWDs. The district hospital was the most common point of contact. Persons with severe disabilities reported higher use of all facility types, particularly high-level hospitals (provincial and central) and private clinics. Consultation and medication services were most commonly sought among PWDs, with the severely disabled more likely to access rehabilitation and medication services.

Use of rehabilitation services, however, remained low with only 15 per cent of persons with severe disabilities reporting access. Among people with mobility, visual or hearing 
and speaking disabilities, approximately 13 per cent used an aid. Eye glasses and crutches were most common with wheelchairs and hearing aids less prevalent. Assistive device usage was more than double among the equivalent severely disabled population (30 per cent) due to increased use of crutches among persons with severe mobility disabilities.

Five per cent of all PWDs required daily care assistance. Severe disabilities were fivefold more likely to require care and at a higher level $(>1 \mathrm{~h})$. Half of persons with severe disabilities participated regularly in work compared with around three-quarters of the general disabled population; 35 per cent of persons with severe disabilities never participated in work (more than double the general disabled population).

Receipt of formal and informal supports was low. Income, healthcare, assist device, gifts or emotional support were received by 9 per cent of the general disabled population and 18 per cent of the severely disabled population. Income was the most common support sourced from government, relatives, community organisations and neighbours in descending order. Five per cent of persons with severe disabilities received government cash transfers and 6 per cent received a free health insurance card.

\subsection{Thematic Analyses}

\subsubsection{Costs of disability}

Healthcare utilisation. Interviews reveal that PWDs were only likely to see a doctor once or twice in their lifetime. Two mentally challenged people have never consulted a doctor. In almost all cases, doctors have informed the family that the disabilities could not be 'cured' and the family had decided not to continue consultations. Economic factors remained an important consideration in determining whether to access healthcare, particularly for people with severe mobility disabilities who were most at risk of positive health expenditures (8/11). Among this group, direct medical expenditures ranged from 3 months to $2 \frac{1}{2}$ year's family income. ${ }^{6}$

At first I went to the Chi Linh hospital but the doctor didn't diagnose anything and said that I had heat exhaustion [say nang]. Later I went to the emergency department at Hai Duong hospital and they said I had suffered a stroke. The hospital fee for a two-month stay was 25 million dong which included 400,000 dong per day for medicine. The Western medicine [antibiotics] didn't work and these days I am taking herbal medicine [thuoc Nam] at 30,000 dong per day which I have been using for about one year now. The tally of my medical fees to date is 30 million dong. I didn't have an insurance card so I had to pay all of the hospital fees. We borrowed the money from the bank [25 million] but we haven't paid it back yet. (Minh, Man, 29 years, Le Loi)

Antibiotic purchases, particularly imported antibiotics, were prohibitively expensive. Instead participants resorted to cheaper, and in some cases less effective, traditional pain relievers.

\footnotetext{
${ }^{6}$ An average monthly income of one million dong was applied, slightly higher than the average annual income quoted in the rural commune (0.86 million dong) and slightly lower than the overall average (1.3 million dong). 
Before we bought medicine [antibiotics] that prevented the disease from developing but that medicine was very expensive so now we just use medicine [herbal] to reduce the pain. (Woman, 41 years, Sao Do)

Health expenditures were considerably lower among persons with severe mental disabilities. The majority of these persons (9/13) had no major medical expenditures with remaining expenditures ranging from 6 days to 4 months' family income. Low spending was in part because of lack of treatment options. Medications were mostly herbal and two people were treating their condition with Paracetamol. A young woman with speaking difficulties had not undergone speech therapy and was treating her condition with daily acupuncture sessions.

Income generation. Households containing a member with severe disabilities were most at risk of income deprivation. This risk was most severe if the person was a main earner with children to support, particularly for rural households which relied upon small cash flows from agriculture. A small number of persons with severe disabilities were able to work around the house, feeding chickens and other livestock, which provided income and was valued by the household.

My left side of my body is paralyzed so I cannot work. My wife works in the field, she has no occupation, and we only have ten lychee trees so it is not enough to meet daily living costs and school fees for my family [two young children]. We don't have anything to sell and we don't have any savings so we have no choice but to borrow from the bank, another 10 million dong. (Minh, Man, 29 years, Le Loi)

Care-giving. The most common care-giving assistance for persons with severe disabilities was bathing which could take 30-60 minutes (13/22). Generally, caring did not impact upon household income; however, there existed potential for persons that required a high level of care (assistance with bathing, toileting, and eating and drinking) (2/13). Persons with severe mental disabilities were more likely to require daily care, and higher levels of care. There was also indication that persons requiring high care placed significantly more psychological stress upon household members. Care giving was a universally accepted family responsibility with the exception of one family who wanted to hire help as the primary carer was too old (84 years).

I must care for her every day. Sometimes I lost sleep because I must take her to go to the toilet during the night. She was very heavy, so it was very difficult to lift her. For forty years I cared for her, I could not work other jobs and it affected our economic situation. It was my responsibility because I am her mother. (Woman, 67 years, Le Loi)

\subsubsection{Coping mechanisms}

Borrowing was the main mechanism employed by households with severely disabled members to meet medical and daily living expenses (16/22). Generally, assets were insufficient in value to sell and households had few savings. The preference was to borrow (interest-free) from relatives and neighbours (11/16) though finance was available from the 
'bank' (commune credit fund) at 1.28 per cent interest per month. Loans were significant relative to monthly incomes, ranging from 1.5 months to 6 years family income. Large loans were typically to finance healthcare costs of the PWD. Reduction of consumption expenditures was common among household with severely disabled members (20/22) and included food, education, shelter and technology.

When you have little you eat little, when you have much you eat much. In difficult times we just eat rice with vegetables and fish sauce. (Woman, 58 years, Le Loi) Our economic situation is very miserable. We don't know if we can find the money to send her [eldest daughter] to upper secondary school next year - she is the smart one, number one in her class. (Woman, 44 years, Le Loi)

I would like to buy a computer for my son and repair the house but where can I find the money. (Woman, 42 years, Le Loi)

Labour substitution within the household was not common due to the availability of finance. However, a woman with an unemployed husband and daughter with multiple disabilities reported working additional hours in the evening at a local restaurant to make ends meet. In another case, two daughters were withdrawn from school to work and care for their incapacitated father whilst their mother went to work in Malaysia to finance costs of disability treatment and debt.

\subsubsection{Informal and formal supports}

Support from relatives, friends or the community was not common. Gifts and money were infrequent, often on the occasion of new year, and not significant in value. Government programmes of monthly income support and free health insurance was the main source of support received by approximately one-third of working age people with severe disabilities. Households, on the whole, were appreciative of the monthly income transfers although acknowledged that the payments were small in value.

Income support is 65,000 dong per month which we receive quarterly. It does have value and helps in one part but is encouragement [dong vien] only. I think the amount should be raised; to eat at the very basic level is 10,000 dong for one person for one day so I think this should be used as the level; that is, 300,000 dong per month is the minimum just to eat. (Man, 52 years, Sao Do)

Health insurance was valued because it exempted certain fees; however, problems of capped benefits, poor quality services and medication, waiting times and administration procedures for members were reported.

The card [healthcare] is good because it exempts consultation and bed fees. Without it, you are dead. But there are some problems. I use the card but I still must pay money to buy medicine and high-level procedures. I do not use the card for medicine because the medicine is not good; if you want good medicine, you must buy it. That is the main problem. The other problem is the waiting time. Cardholders must consult in a separate area, which is crowded. Sometimes I must wait a whole morning to see a doctor and, if I can't see a doctor in the morning, then I must return in the afternoon. Also, at the hospital, when you carry a card, you must pass through many procedures and waste a lot of time. Therefore, not to use the card and go to a private doctor is better. You know, generally, to enter a hospital in Viet Nam is not easy. So I just use 
the card when I have to stay in hospital. I do not have to pay bed fees and that is very good. (Man, 42 years, Sao Do)

\subsubsection{Health and welfare}

All but three households with severely disabled members reported that their physical or mental health was affected by living with a severely disabled member (19/22). Regular sleep loss was reported in one-third of cases, two households reported weight loss and three households reported taking medication to assist with sleep or headaches. Worry over the immediate economic situation of the household and that of the future, when there may be nobody to care for and support the PWD, were cited as the main contributing factors affecting household welfare.

My wife worries a lot about our economic situation. She cannot sleep and must take medicine [thuoc than kinh (tranquilisers)] to help her sleep. (Man, 29 years, Le Loi)

We worry about when there will be no one to take care of her [daughter with disabilities]. Sometimes my wife wakes in the night and cannot sleep. So now we are trying our best to get treatment for her [daughter]. (Man, 52 years, Sao Do)

\section{DISCUSSION}

\subsection{Disability and Poverty}

Relative to other site residents, PWDs experience higher rates of poverty by both measures. Absolute poverty rates are approximately double for the derived measure and more closely reflect national estimates, which suggest local methods of identifying poor households are stringent. There is little difference in poverty by disability degree. This is likely because measures are determined for the household as a whole, and appropriated per capita in the case of the asset index measure, hence do not directly measure individual poverty levels. This explanation of measurement bias is further supported by marked differences in individual poverty-correlates and need-indicators between persons with severe disabilities and the general disabled population. This is also observed in qualitative interviews. Five persons with non-severe disabilities experienced no significant economic costs associated with their disability.

Interviews among households containing severely disabled members provided valuable insights into the processes linking disability and poverty. Healthcare expenditures pose significant economic burden. This is particularly the case for households with members with severe mobility disabilities, consistent with report from India (Erb and Harriss-White, 2002). Medical expenditures among people with severe mental disabilities are low owing to fewer treatment options, as commonly reported in developing countries (Das et al., 2007). Medication usage is limited to herbal remedies and Paracetamol provided free of charge by the commune health station. There exists a psychiatric hospital in a neighbouring province but few persons sought specialist treatment. This may be because doctors are more likely to label mental disabilities as 'incurable' and or reluctance on the part of families to explore treatment options for mental illness. 
Income deprivation is most serious if the household loses a main earner through disability and has children to support, similar to findings in India and Bangladesh (Erb and Harriss-White, 2002; Foley and Chowdhury, 2007). School fees are particularly burdensome. Interviews reveal that there is potential to impact on the earnings of primary carers for persons which require a high level of care $(>1 \mathrm{~h}$ daily) representing approximately 15 per cent of persons with severe disabilities or 3 per cent of the general disabled population. Similarly, in India, care-giving duties do not constitute a major economic burden for the majority of households (Erb and Harriss-White, 2002). Four per cent of cases were sufficiently disabled to be completely unable to look after themselves and caring is assumed to be coped with by an increase in female domestic labour (Erb and Harriss-White, 2002). However, carers are likely precluded from formal-wage positions to form an additional indirect cost associated with disability.

Common coping strategies employed by households to manage the economic costs of disability include treatment avoidance, debt-financing and reducing consumption expenditures, consistent with other low-income settings (Erb and Harriss-White, 2002; Foley and Chowdhury, 2007). Although most PWDs at the study site report consulting a doctor in their lifetime, interviews reveal that the frequency of visits is small (generally once or twice). Treatment avoidance can contribute to disability and thereby household vulnerability. The majority of loans are sourced interest-free through social networks yet almost all households reduce consumption expenditures and experience adverse health affects which suggests that loans threaten welfare. Households lacking social capital, or those with medical bills too large to be sourced informally, undertake interest bearing loans, placing them at greatest risk of adverse consumption and health effects.

\subsection{Social Protection}

Site coverage of formal social protection programmes is surprisingly low. This was thought as due to high number of persons with severe disabilities above programme eligibility age (60 years). However, recipient rates change little for adults below 60 years of age. Site coverage is significantly lower than reported in qualitative interviews likely because the two communes chosen for survey have the highest recipient rates among the seven site communes. Low overall coverage likely reflects local administrative capacities. Commune officials identify beneficiaries, yet it remains unclear how eligibility is determined. Programmes address primary needs of income and healthcare support but are formulated at a high level of generality. Cash transfers are insufficient to cover minimum daily food intake whereas health insurance provides protection against low-grade outpatient expenditures but is unsatisfactory for inpatient and medication expenditures to which severely disabled persons are prone. Of particular concern is the relatively high use of costly provincial and central hospital services among the severely disabled population.

\subsection{Study Limitations}

This study is limited by the geographic homogeneity of one district in one northern province. Methods of analysis are descriptive and do not control for the presence of confounding factors. Results should therefore be viewed as preliminary. Furthermore, the study is not exhaustive in the measurement of disability costs (Jones and O'Donnell, 1995; 
Erb and Harriss-White, 2002), coping mechanisms (Sauerborn et al., 1996) or the range of factors enabling or constraining access to support systems (Goudge et al., 2009). We are unable to give due attention to the gendered and spatial aspects of disability and poverty (Erb and Harriss-White, 2002; Hoogeveen, 2005; Foley and Chowdhury, 2007). Longitudinal study design is necessary to assess the long-term implications of coping mechanisms for household welfare. This is particularly pertinent due to the long-term nature of disability.

\section{CONCLUSION}

Results support recent efforts of the Vietnamese government to extend formal mechanisms of social protection for households containing members with severe disabilities. Considerable challenges lie ahead in incorporating a higher level of disability targeting into mainstream programmes, both in terms of eligibility and of benefit levels. The inability to perform a selection of ADLs is tentatively proposed as a valid screening tool and is more readily identifiable than poverty-based social protection eligibility criterion. However, further testing is required. Other considerations arising from this research include developing the provision of rehabilitation services (including assistive aids) particularly for mental and sensory disabilities; 'bare-foot doctor' and CBR services in view of the commonly encountered belief that impairments cannot be rehabilitated; low or no-interest loans for households with low social capital; free education for dependents of persons with severe disabilities; and supplementary income and respite services for households with members requiring a high level of care.

\section{ACKNOWLEDGEMENTS}

The authors thank the CHILILAB and the Hanoi School of Public Health for facilitating this research. Special thanks also go to the households who generously gave their time to participate in this study. Comments from two anonymous referees are gratefully acknowledged. This research was funded by the China Medical Board of New York, and an Australian Post-graduate Award and supplementary scholarship from the National Centre for Epidemiology and Population Health (The Australian National University) for the lead author. The views expressed in this paper are those authors alone.

\section{REFERENCES}

Barnes C. 2003. What difference a decade makes: reflections on doing 'emancipatory' disability research. Disability \& Society 18(1): 3-17.

Booysen F, Van-der-Berg S, Burger R, Von-Maltitz M, Rand GD. 2008. Using an Asset Index to assess trends in poverty in seven Sub-Saharan African countries. World Development 36(6): 11131130.

Braithwaite J, Mont D. 2008. Disability and poverty: a survey of World Bank poverty assessments and implications. SP Discussion Paper.

Das J, Do Q-T, Friedman J, McKenzie D, Scott K. 2007. Mental health and poverty in developing countries: revisiting the relationship. Social Science \& Medicine 65: 467-480. 
Elwan A. 1999. Poverty and disability: a survey of the literature. Washington, DC, Social Protection Unit, Human Development Network, The World Bank.

Erb S, Harriss-White B. 2002. Outcast from social welfare: adult disability, incapacity and development in rural South India. Bangalore, Books for change.

Filmer D, Pritchett LH. 2001. Estimating wealth effects without expenditure data - or tears: an application to educational enrollments in states of India. Demography 38(1): 115-132.

Foley D, Chowdhury J. 2007. Poverty, social exclusion and the politics of disability: care as a social good and the expenditure of social capital in Chuadanga, Bangladesh. Social Policy and Administration 41(4): 372-385.

Giang LT, Pfau WD. 2009. Vulnerability to Vietnamese elderly to poverty: determinants and policy implications. Asian Economic Journal 23(4): 419-437.

Glendinning C, Baldwin S. 1988. The costs of disability. In Money Matters: Income, Wealth and Financial Welfare, Walker R, Parker G (eds). Sage Publications, Inc.: London.

Glewwe P, Agrawal N, Dollar D (eds). 2004. Economic Growth, Poverty, and Household Welfare in Vietnam. The World Bank: Washington.

Gooding K, Marriot A. 2009. Including persons with disabilities in social cash transfer programmes in developing countries. Journal of International Development 21: 685-698.

Goudge J, Russell S, Gilson L, Gumede T, Tollman S, Gills A. 2009. Illness-related impoverishment in rural South Africa: Why does social protection work for some households but not others? Journal of International Development 21: 231-251.

GSO. 2008. Household Living Standards Survey Results Summary (Ket Qua Tom Tat Khao Sát Muc Song Ho Gia Dinh Nam 2006). Hanoi The General Statistics Office of Viet Nam, available at: http://www.gso.gov.vn/default.aspx?tabid=507\&idmid=\&ItemID=6932.

Haveman R, Wolfe B. 2000. The economics of disability and disability policy. In Handbook of Health Economics, Culyer AJ, Newhouse JP (eds). Elsevier: Amsterdam.

Hoogeveen JG. 2005. Measuring welfare for small but vulnerable groups: poverty and disability in Uganda. Journal of African Economies 14(4): 603-631.

HSPH. 2008. Demographic and Epidemiological Surveillance System in CHILILAB: An Introduction and Research Findings 2004-2006. Medical Publishing House: Hanoi (HSPH: Hanoi School of Public Health).

Jette AM. 1994. How measurement techniques influence estimates of disability in older populations. Social Science \& Medicine 38(7): 937-942.

Joint Donor Group. 2003. Poverty: Vietnam Development Report 2004. Printing and Cultural Product Company: Hanoi.

Jones A, O'Donnell O. 1995. Equivalence scales and the costs of disability. Journal of Public Economics 56: 273-289.

Kett M, Lang R, Trani J-F. 2009. Disability, development and the dawning of a new convention: A case for optimism? Journal of International Development 21: 649-661.

Le DB, Dang AN, Khuat HT, Le TH, Bach RL. 2005. Social Protection for the Most Needy in Vietnam. Thegioi: Hanoi.

Mitra S. 2005. Disability and social safety nets in developing countries. Social Protection Discussion Paper Series. The World Bank: Washington, DC.

MOLISA. 2006. National Plan to Support People with Disabilities: Period, 2006-2010. Hanoi, Ministry of Labour, Invalids and Social Affairs. Socialist Republic of Viet Nam.

Ordinance on Disabled Persons. 1998. (Phap lenh ve nguoi tàn tat. 06-L/CTN.) Socialist Republic of Viet Nam.

Regulation 67. 2007. Policies to assist subjects of social security (Nghi dinh ve chinh sách tro giúp các doi tuong bào tro xa hoi). The Socialist Republic of Viet Nam. 67/2007/ND-CP. 
Sauerborn R, Adams A, Hien M. 1996. Household strategies to cope with the economic costs of illness. Social Science and Medicine 43(3): 291-301.

United Nations. 2006. International Convention on the Rights of Persons with Disabilities: Some Facts about Persons with Disabilities. New York, United Nations, available at: http://www.un.org/ disabilities/convention/pdfs/factsheet.pdf.

van-de-Walle D. 2001. Sources of ethnic inequality in Viet Nam. Journal of Development Economics 65: 177-207.

Weiner JM, Hanley RJ, Clark R, Nostrand JFV. 1990. Measuring the activities of daily living: comparisons across national surveys. Journal of Gerontology 45(6): S229.

WHO. 2001. International Classification of Functioning, Disability and Health. World Health Organization: Geneva. 